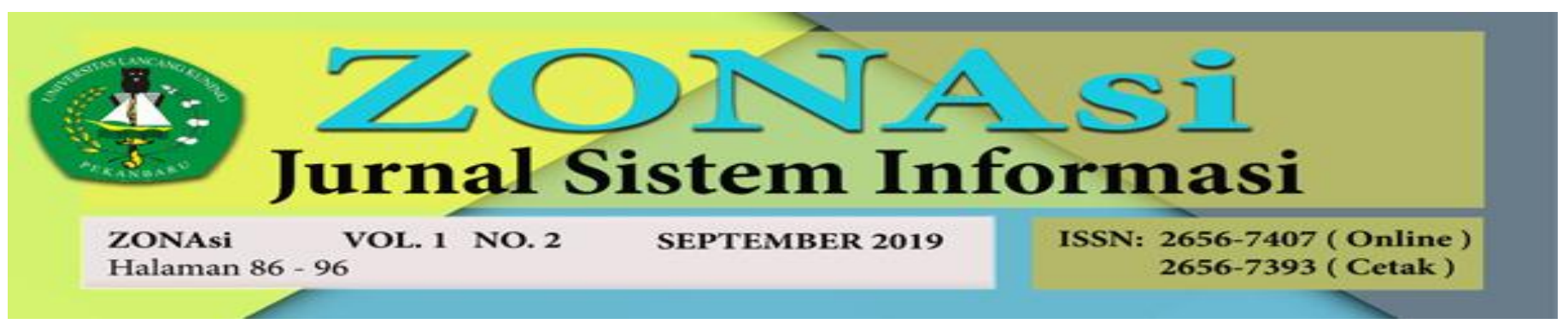

\title{
PERANCANGAN ANTAR MUKA APLIKASI PEMESANAN FOTOGRAFI DAN \\ MAKE UP BERBASIS ONLINE PADA QUEEN PHOTO STUDIO PADANG
}

\author{
Arman $^{1}$, Liranti Rahmelina ${ }^{2}$, Sotar $^{3}$, Yuliana Siska $^{4}$ \\ ${ }^{1,2,3,4}$ STMIK Indonesia Padang \\ Sistem Informasi STMIK Indonesia Padang \\ Jln. Khatib sulaiman dalam No.1 Padang, telp. 07517056199 \\ e-mail: ${ }^{1}$ arman@ stmikindonesia.ac.id, ${ }^{2}$ lirantirahmelina@ stmikindonesia.ac.id, \\ ${ }^{3}$ sotar@stmikindonesia.ac.id, ${ }^{4}$ yuliana_siska@gmail.com
}

\begin{abstract}
Abstrak
Penelitian ini dilakukan untuk membuat suatu aplikasi pemesanan fotografi dan make up secara online. Fokus dalam penelitian ini adalah pembuatan sistem pemesanan online dengan menggunakan bahasa pemograman yang telah digunakan yaitu PHP dan MySQL. Metode pengumpulan data dalam penelitian ini mengenai pemesanan online fotografi dan makeup pada Queen photo studio Padang. Penelitian ini menunjukkan hasil bahwa pemesanan yang masih bersifat manual tentu menyulitkan dari pihak pelanggan maupun dari pihak administrasi, karena bagian administrasi sistem pemesanan masih berupa kertas manual membuat kemungkinan data hilang atau rusak dan mengalami kesulitan dalam merekap data pelanggan. Pelanggan yang mengalami kesulitan dalam mendaftar dibagian administrasi karena harus mengantri dengan pelanggan lain, sehingga sistem tersebut dikategorikan tidak efektif dan efisien baik dari pihak pelanggan maupun ke pihak administrasi. Oleh karena itu peneliti merancang sistem informasi pemesanan online pada Queen photo studio padang yang bertujuan agar mempermudah pihak Queen dan pelanggan. Metode yang digunakan adalah metode OOP dengan model air terjun(waterfall) dan menggunakan Unified Modeling Language sebagai alat bantu pengembangan system dan menggunakan $P H P$ dan $M y S Q L$.
\end{abstract}

Kata kunci: Sistem, Informasi, Penesanan, Fotografi Dan Make Up, Berbasis Online

\section{Pendahuluan}

Internet merupakan sebuah pengembangan teknologi [1] informasi [2] dalam berkomunikasi dengan user yang lain di bantuan media sistem informasi [3]. Komunikasi yang digunakan untuk berhubungan dengan orang lain, komunikasi yang dihubungkan dengan berbagai aplikasi seperti Website [4], Email [5] dan aplikasi Sekolah [6], Perkantoran [7]. Kota Padang merupakan ibu kota provinsi Sumatra Barat, pengguna internet sudah banyak juga. Penggunan internet memanfaatkan untuk segala kegiatan, baik bisnis maupun pemerintahan untuk mendapatkan informasi maupun kebutuhan lainnya. Salah satu gunanya adalah sebagai media promosi produk dan jasa [8], media transaksi bisnis dan jasa [9], pemasaran suatu produk atau barang dan jasa [10]. Internet menawarkan kemudahan transaksi online yang bisa dilakukan dimana saja dan kapan saja tanpa harus mendatangi langsung tempat penjualan barang atau jasa tersebut [11]. 
Masyarakat saat ini tidak ingin membuang waktu dan tenaga dalam melakukan transaksi, hal ini membuat banyak bisnis menyediakan barang dan jasa mereka melalui internet. Pemesanan online pun dimanfaatkan oleh banyak usaha toko maupun usaha studio photo [12].

Di kota padang terdapat 54 perusahan, UMK Dan UMKM yang bergerak dibidang studio photo, ada yang sudah penggunakan internet dan ada juga yang belum, (sumber : Google map.com) salah satu dari sekian banyak studio photo tersebut satunya adalah Queen photo studio yang merupakan studio photo dan jasa tata rias (make up) yang cukup terkenal dikota Padang, hal ini didasari oleh banyaknya pelanggan yang mendatangi Queen photo studio untuk menggunakan jasa mereka seperti yang diungkapkan oleh salah 1 karyawan Queen photo studio yang menyatakan bahwa hampir setiap hari Ia melayani lebih dari 25 orang pelanggan untuk menggunakan jasa make up maupun fotografi.

Berbagai kalangan menggunakan jasa photographer maupun jasa tata rias pada Queen seperti kalangan mahasiswa/i, pegawai, maupun masyarakat sekitar, terdapat beberapa paket photo maupun paket make up di Queen studio dengan harga yang bersahabat, Dengan banyaknya peminat membuat studio Queen selalu didatangi pelanggan.

Masalah yang selama ini dihadapi adalah pemesanan yang masih bersifat manual tentu menyulitkan dari pihak pelanggan maupun dari pihak administrasi, karena bagian administrasi sistem pemesanan masih berupa kertas manual membuat kemungkinan data hilang atau rusak dan mengalami kesulitan dalam merekap data pelanggan. Pelanggan yang mengalami kesulitan dalam mendaftar dibagian administrasi karena harus mengantri dengan pelanggan lain, sehingga sistem tersebut dikategorikan tidak efektif dan efisien baik dari pihak pelanggan maupun ke pihak administrasi.

Penerapan e-commerce dapat meningkatkan keunggulan bersaing dari perusahaan dan juga dapat membutuhkan strategi diputuskan oleh manajemen dari perusahaan untuk mempersiapkan sumber daya manusia menggunakan teknologi handal untuk pemasaran sebuah produk mekanisme pelayanan dan transaksi yang cepat dan singkat dengan keamanan yangbaik.Menjalin kerja sama yang baik dengan para supplier dan distributor. Jika semua hal diatas dapat dilakukan dengan baik akan dapat meningkatkan keunggulan bersaing yang dimiliki perusahaan.

Beberapa peneliti yang telah melakukan penelitian adalah [13] dengan judul penelitian Perancangan Sistem Informasi Administrasi Jasa Photo Pernikahan Berbasis Web Pada Europhia Photo Studio, penelitian ini menghasilkan sistem informasi administrasi jasa foto berbasis web pada Euphoria Photo Studio yang dapat memudahkan dalam pengelolaan transaksi pemesanan jasa foto. Pemesan dapat memesan paket photo secara online. Pelanggan bisa mengetahui harga karna sistem bisa mengkalkulasikan harga.

Peneliti [14] maka dibuatlah sistem informasi berbasi online yang dapat menampung kegiatan komunitas, mengolah data, pemesanan jasa fotografer, data agenda/kegiatan, maupun data iuran agar menjadi satu wadah kreatifitas yang bermanfaat untuk para anggota seniman photography pada komunitas Jepret Mentaya Sampit.

Penelitian oleh [15] dengan judul penelitian Perancangan Dan Pembuatan Sistem Informasi Penyewaan Kamera Dan Perlengkapan Studio Foto Berbasis Web Studi kasus Pada Toko Rumah Foto yang menghasilkan sebuah sistem online untuk pemesanan penyewaan kamera, dan membuat laporan penjualan serta laporan penyewaan. 
Berdasarkan dari beberapa penelitian dari peneliti diatas dapat disimpulkan bahwa perlu setiap usaha, pemasarkan produknya, baik jasa maupun yang lainnya perlum memgunakan sara teknologi yang berbasis online. Dengan menggunakan teknologi berbasis online, nantinya mereka dapat bersaing dengan perusahan sejenis maupun dengan perusahsa nlain . dengan memnamfatkan teknologi maka perusahan dapat untuk menghasilkan omset lebih tinggi lagi, selain itu perushan dapat juga membah pelanggan yang luas dan lebih banyak lagi dari tahun sebelumnya. Sesuai dengan misi dan visi dari perusahan masing-masing, dan sesuai juga dengan tujuan perusahan untuk masa sekarang dan untuk masa yang akandatang lebih maju lagi dan penjualannya juga meningkat setiap saat.

\section{Tinjauan Pusataka}

\subsection{Pengertian Perancanga}

Perancangan merupakan langkah awal yang dilakukan dalam membangun sebuah aplikasi. Menurut [16] Perancangan merupakan langkah awal yang dilakukan dalam membangun sebuah aplikasi yang akan dirancang sesuai dengan gungsinya yang sudah ditemtukan oleh perancang program.

\subsection{Metode OOP}

Perancangan sistem yang dibangun akan menggunakan konsep Object Oriented Programming (OOP) untuk memudahkan pengembangan lebih lanjut, karena menggunakan konsep OOP maka perancangan pada pembuatan sistem ini menggunakan UML untuk mempermudah pengembang dalam membangun sistem pendaftaran online ini. [17] UML adalah bahasa pemodelan untuk sistem atau perangkat lunak yang berparadigma berorientasi objek. Pemodelan sesungguhnya digunakan untuk penyederhanaan permasalahan-permasalahan yang kompleks sedemikian rupa sehingga lebih mudah dipelajari dan dipahami.yaitu antara lain nya :

\section{Analisis sistem}

Pada tahap ini merupakan analisa kebutuhan sistem. Proses ini dimulai dari pengumpulan data-data dengan cara observasi wawancara serta quisioner sebagai bahan pengembangan sistem.

2. Desain sistem

Desain sistem dilakukan dengan merancang sebuah sistem kedalam bentuk diagram yang akan digunakan sebagai model sistem yang dirancang. Diagramyang akan digunakan nantinya adalah use case diagram, activity diagram, class diagram dan sequence diagram.

3. Implementasi sistem

Desain yang dibuat diimplementasikan ke dalam bahasa pemograman agar dapat dimengerti oleh mesin komputer. Penerjemahan nantinya akan menggunakan bahasa pemograman $p h p$ dan $M y S q l$ sebagai perancangan database.

4. Pengujian sistem

Pengujian sistem berfungsi untuk memastikan apakah sistem sesuai dengan output yang diinginkan agar kesalahan (eror) dapat diminimalisir. Pengujian sistem yang dilakukan dengen menggunakan metode blackbox.

5. Perawat sistem

Pemeliharaan sistem merupakan suatu kombinasi dari berbagai tindakan yang dilakukan untuk menjaga suatu sistem dalam, atau memperbaikinya sampai suatu kondisi yang bisaditerima. 


\subsection{Pengertian Database}

Pengertian Database Basis data (database) adalah suatu pengorganisasian sekumpulan data yang saling terhubung yang lain sehingga memudahkan aktivitas untuk mendapatkan informasi yang dibutuhkan oleh user. Basis data dimaksudkan untuk mengatasi permasalahan pada sistem yang menggunakan berbasis berkas. Sehingga untuk mengelola basis data diperlukan sebuah perangkat lunak yang disebut Database Management System (DBMS)[18].

\subsection{Pengertian MySQL}

MySQL adalah sebuah aplikasi database server yang mampu menerima dan mengirimkan datanya dengan sangat cepat, multi user serta menggunakan perintah standart SQL (Structured Query Language) [19]

\subsection{Sekilas PHP}

PHP adalah bahasa pemrograman yang berupa scripting, cara kerja sistemnya dari program sebagai interpreter bukan compiler. Maksudnya semua sintaks yang dikirimkan akan sepulihnya akan dijalankan pada sebuah server, sedangkan yang data yang dikirimkan ke browser hanya berupa ouputnya aja [20]

\section{Metode Penelitian}

Metode yang digunakan dalam pengembangan sistem adalah Web engineering, metode ini merupakan rekayasa web menggunakan konsep rekayasa perangkat lunak secara teknis pada aktifitasnnya.tujuan wen engimering ini adalah menyusun sistem yang baru untuk memecahakan masalah pada sistem yang lama. Pada metode wen engjimering terdiri dari lima tahap yaitu [21] :

3.1. Customer komunikasi

3.2. Perencanaan

3.3. Modeling

3.4. Pembangunan aplikasi

3.5. Deployment

\section{Hasil Dan Pembahasan}

Hasil penelitian sistem dijabarkan pada bagin ini, bagaimana sebuah sistem manual yang telah bertransformasi menjadi sebuah sistem online yang terkomputerisasi dan dengan adanya pemesanan online ini pihak Queen photo studio sudah tidak kesulitan lagi untuk merekap data pelanggan karena sudah menggunakan aplikasi yang terkomputerrisasi, Dari beberapa kegiatan implementasi sistem dimulai dari halaman utama untuk login untuk admin dan pelanggan, untuk lebih jelas menu utama untuk pilihan paket dapat dilihat pada Gambar. 1. 


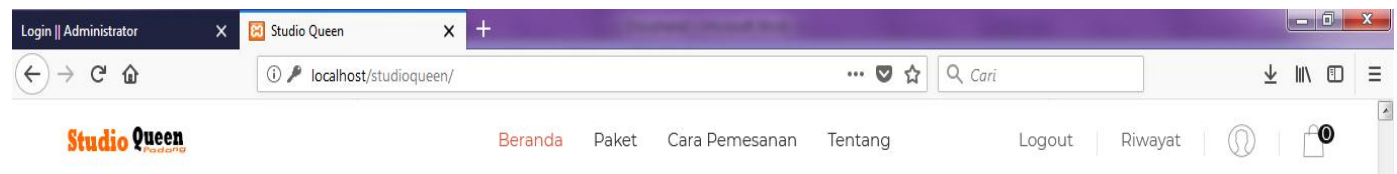

\section{PAKET UNGGULAN}

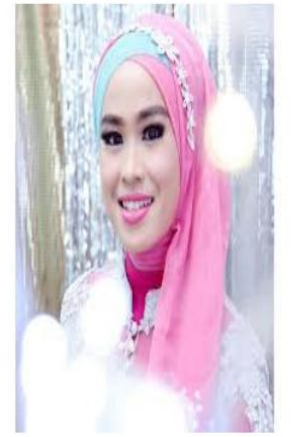

paket Make Up

IDR 400,000

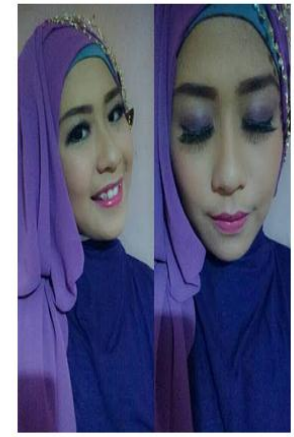

Make Up Wisuda IDR 350,000

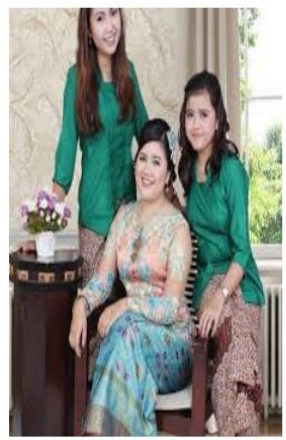

Make Up Event IDR 450,000

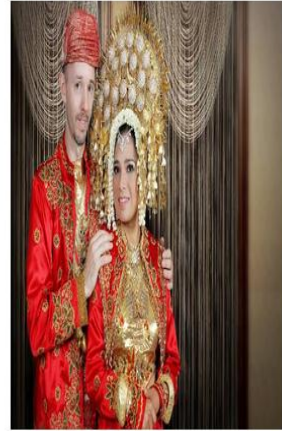

Fotografi Wedding IDR 900,000

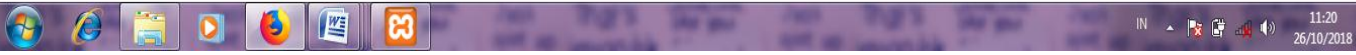

Gambar 1. Halaman Menu Pilihan Paket

\subsection{Menu input}

a. From Input data Data Paket

Pada tampilan menu Input membantu pengguna untuk memasukkan data ke dalam sistem. Data yang dapat dimasukkan yaitu data paket, data kategori paket yang di Inputkan oleh admin dan data pelanggan di Inputkan oleh pelanggan itu sendiri ketika membuat akun. Tampilan Input data paket ditunjukkan pada Gambar 3.

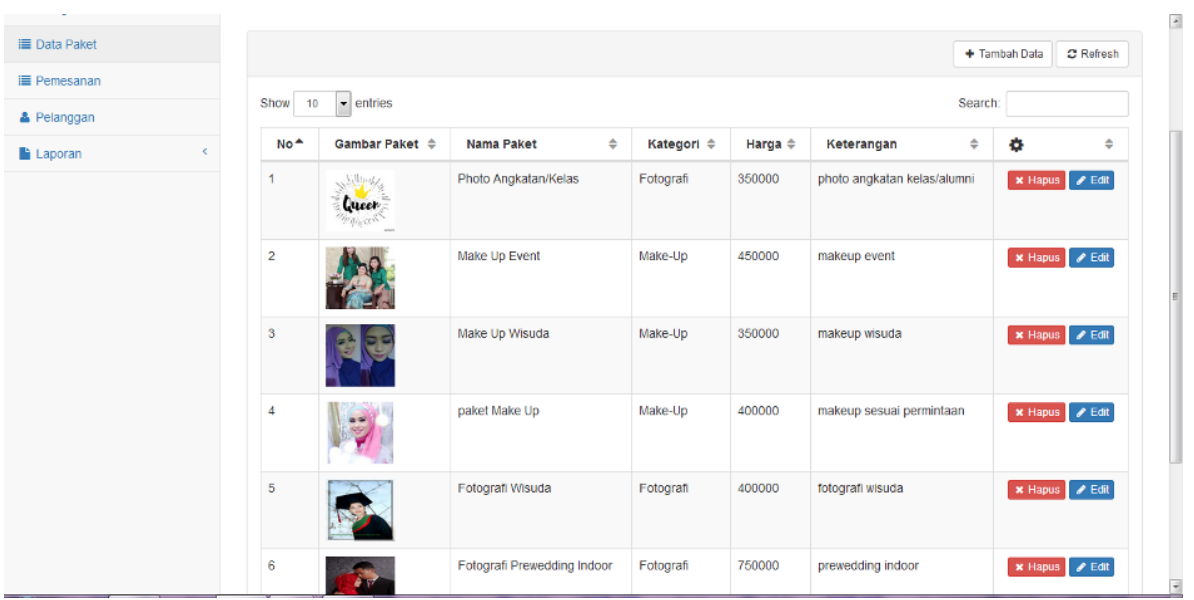

Gambar 3. Halaman Input Data Paket

b. From Input Data Kategori Paket

Tampilan kategori paket merupakan tampilan kategori paket yang ada pada aplikasi pemesanan online jasa fotografi dan makeup padda Queen photo studio, dan 
di situ kita juga bisa menambah,mengedit, menghapus ketegori tersebut seperti pada gambar 4.

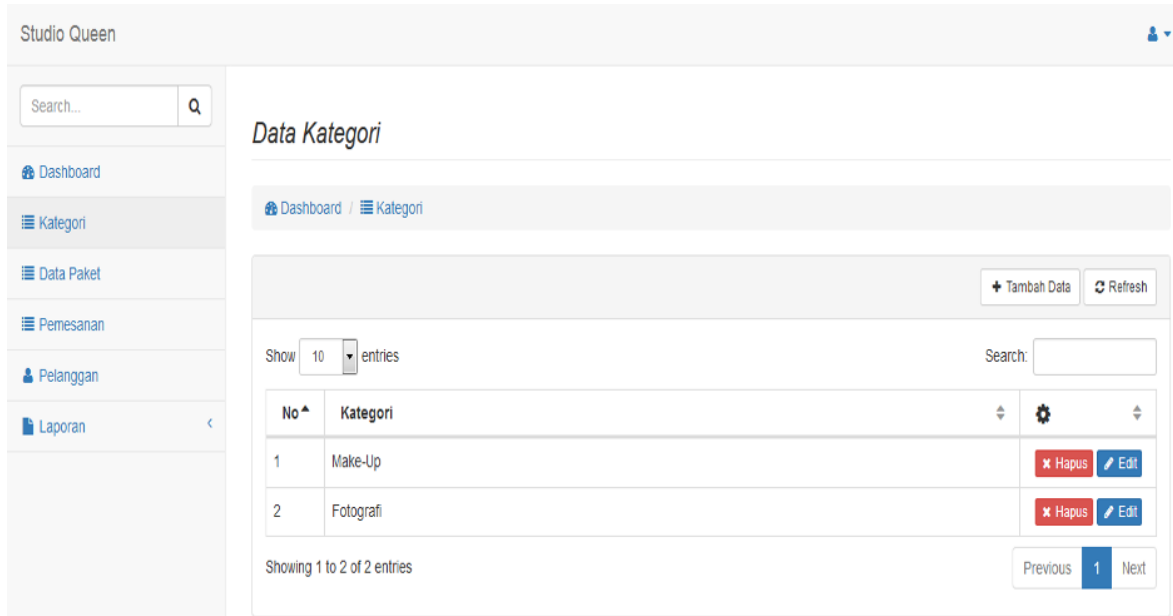

Gambar 4. Halaman Input Data Kategori Paket

\section{c. From Input Data Pelanggan}

Input data pelanggan berguna untuk menginputkan data pelanggan ketika pelanggan membuat akun utuk masuk ke sistem, pelanggan bisa mendaftar dulu dan melengkapi data yg di mintak sistem dan jika sudah selesai ,pelanggan bisa lansung masuk ke dalam sistem .Seperti pada Gambar 5.

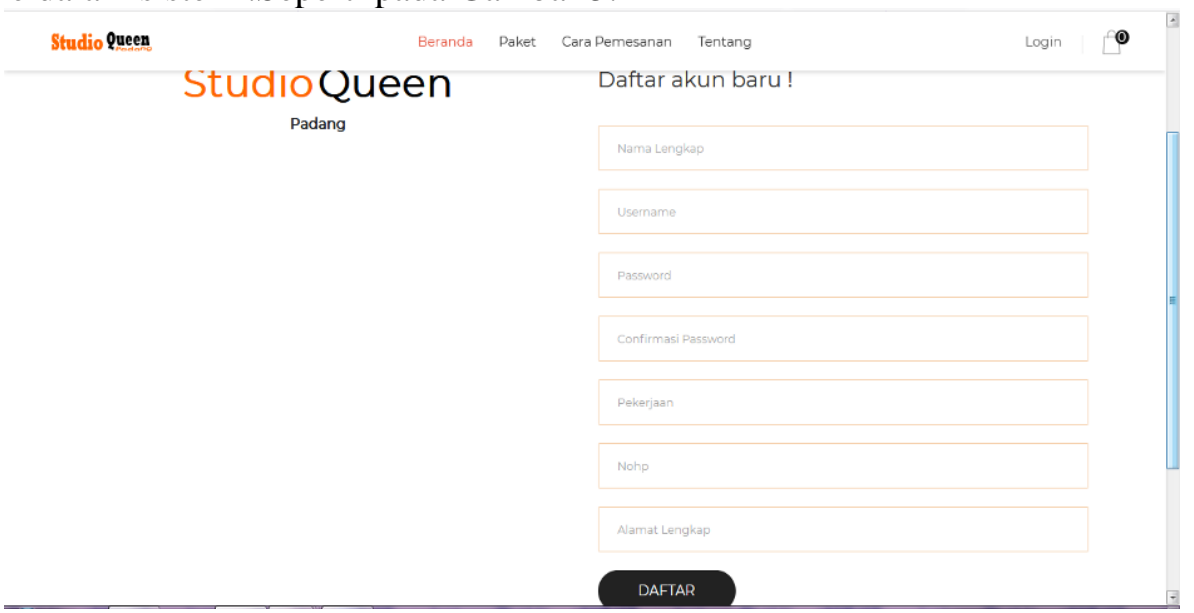

Gambar 5. Halaman Input Data Pelanggan

\subsection{From Halaman Tampilan Proses}

a. From Menu Proses Pemilihan Paket

Setelah pelanggan memilih paket yang di inginkan, maka pemesanan akan masuk ke keranjang pelanggan, dapat dilihat ada beberapa menu ada menu pilihan kategori yg berisikan kategori fotografi, kategori make up dari situ pelanggan bisa memilih yang di inginkan, setelah itu pelanggan bisa memasukan ke dalam keranjang dan jika untuk fotografi pelanggan dapat memilih ukuran yang di inginkan untuk poto tersebut. untuk lebih jelas dapat dilihat pada Gambar 7. 


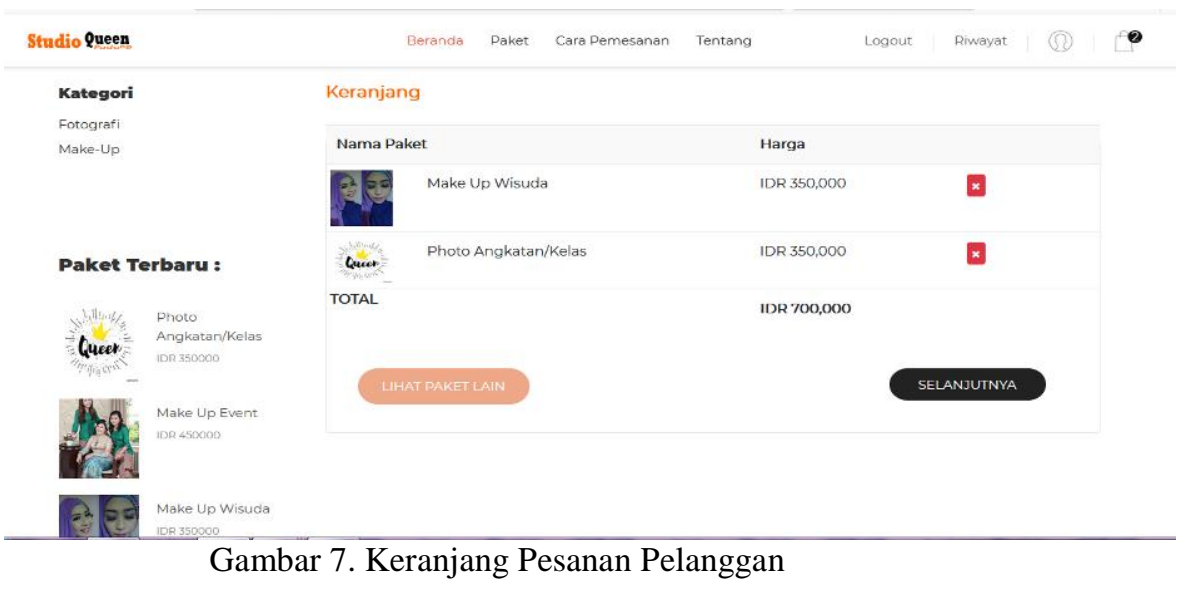

b. From Menu Proses Informasi Pesanan Pelanggan

Setelah pelanggan memilih paket,dan memasukan paket ke dalam keranjang maka pelangan bisa melihat informasi pesanan yang akan dipesan, dapat dilihat seperti informasi pesanan di bawah ini, di situ terlihat dengan nama suci,notlp,alamat dan informasi jasa yang dipesan. Untuk lebih jelas dapat dilihat Gambar 8.

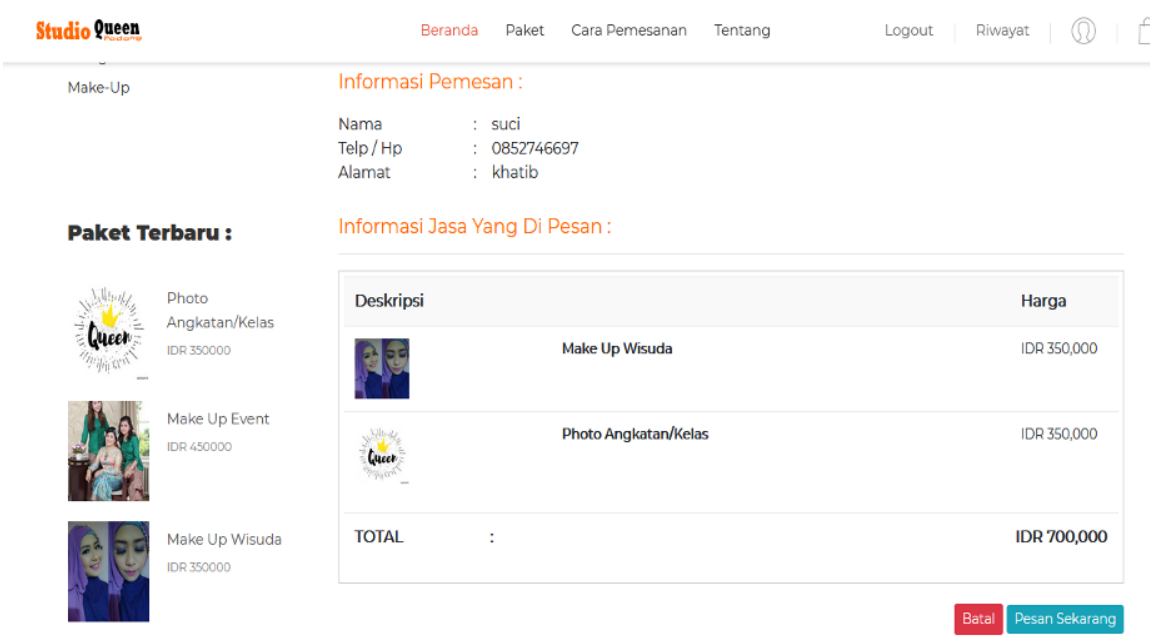

Gambar 8. Informasi Pesanan Pelanggan

c. From Tampilan Riwayat Pesanan

Pelanggan pun bisa melihat riwayat pesanan, yg dijelaskan di bagian riwayat pesanan ada kode pemesanan,tanggal,jam dan total harga ,jadi pelanggan bisa melihat di sini riwayat pesanan yg pelanggan lakukan .seperti terlihat pada Gambar 10. 


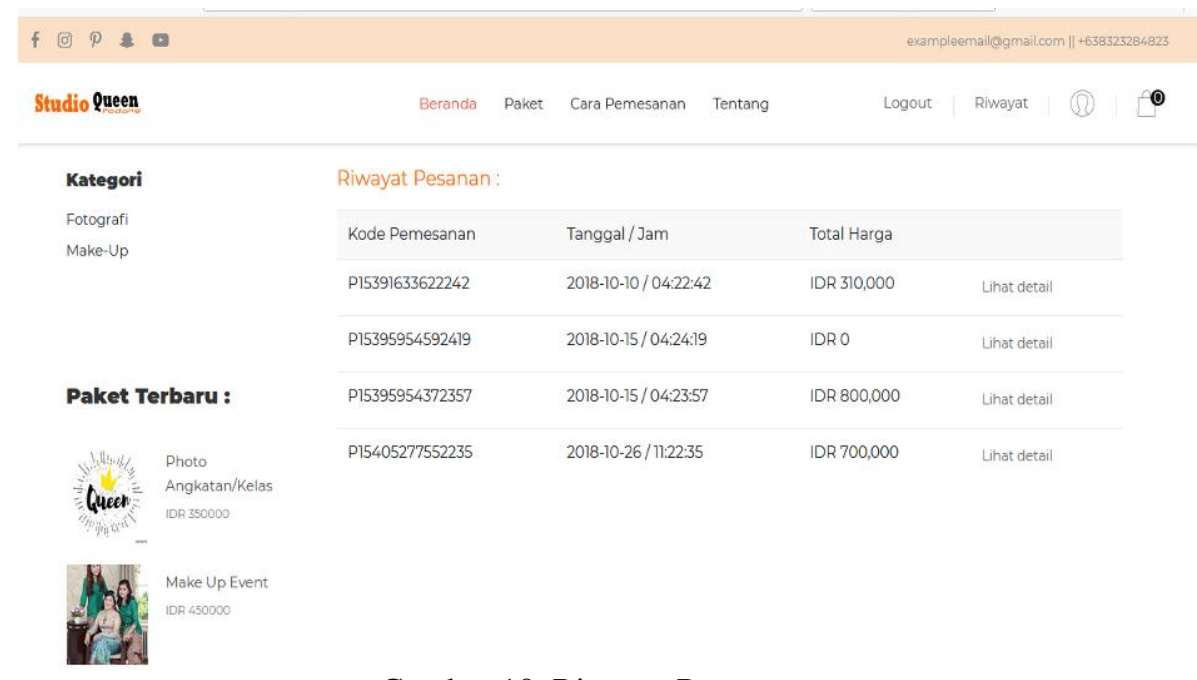

Gambar 10. Riwayat Pesanan

\section{d. From Tampilan Proses Pemesanan Oleh Admin}

Proses pemesanan oleh admin, admin akan memproses pesanan pada aplikasi, admin bisa memproses pesanan maupun membatalkan pesanan, dijelaskan pada detail pesanan terdapat pilihan proses pesanan dan batalkan pesanan. Seperti terlihat pada Gambar 11.

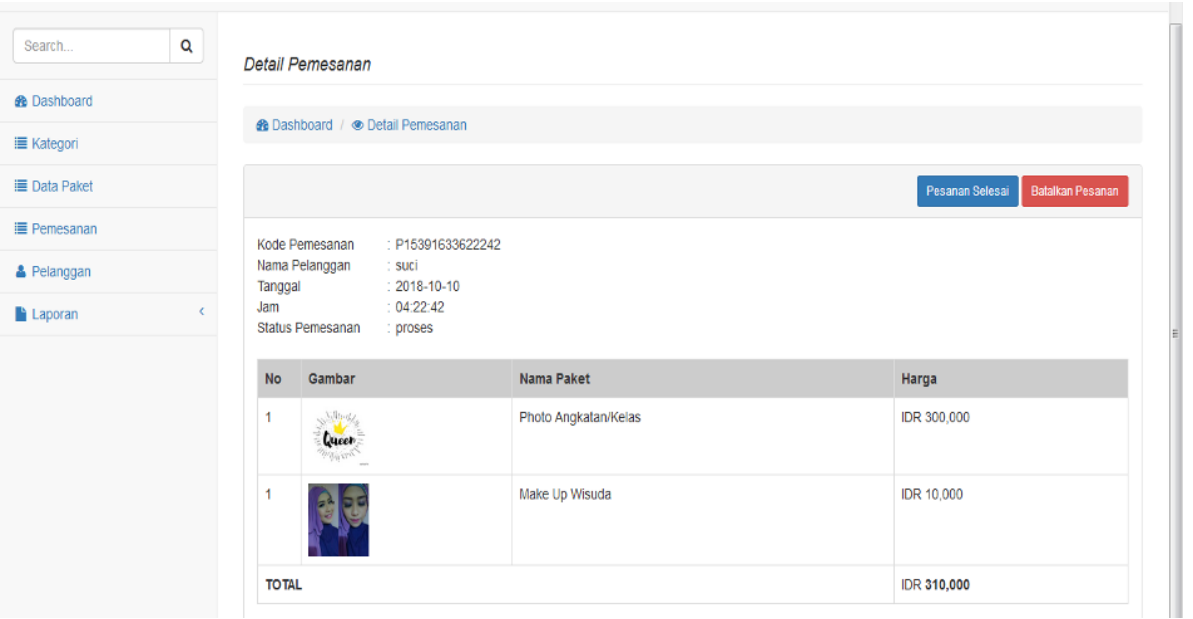

Gambar 11. Proses Pesanan Oleh AdminTampilan Output

a. Laporan Data Pemesanan

Pada tampilan Output atau laporan pada menu admin menampilkan data yang sudah dimasukan dan dikelola oleh sistem, terlihat pada data pemesanan paket terdapat keseluruhan pemesanan yang di lakukan oleh pelanggan. Dilihat pada Gambar 12. 


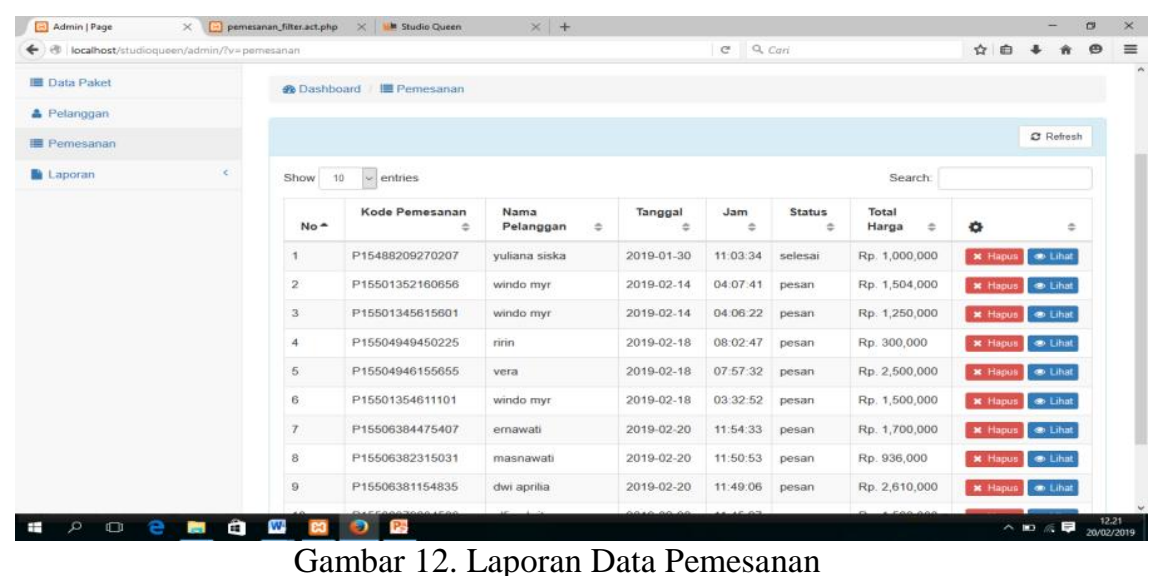

b. Laporan Bukti Pemesanan

Laporan bukti pemesanan merupakan bukti pemesanan yang di miliki pelanggan ketika telah selesai memesan jasa yang berbentuk pdf dan bisa dicetak/diprint, seperti terlihat pada Gambar 15.

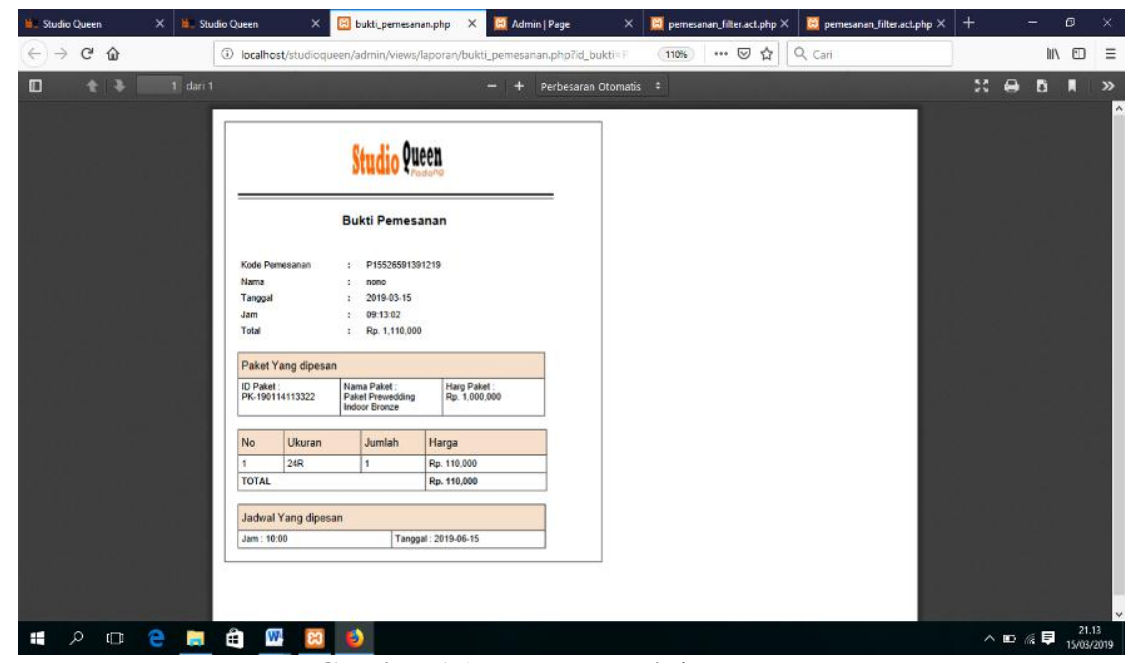

Gambar 15. Laporan Bukti Pemesanan

\section{Kesimpulan}

Sehubungan dengan analisis yang dilakukan pada Queen photo studio Padang dengan metode penelitian yang telah diuraikan pada bab-bab sebelumnya dapat disimpulkan bahwa :

1. Dengan adanya aplikasi ini, Queen photo studio sudah tidak menggunakan media kertas lagi dalam menerima pemesanan dari pelanggan.

2. Jadi Pihak Queen photo studio sudah tidak kesulitan lagi untuk merekap data pelanggan karena sudah menggunakan aplikasi yang terkomputerisasi. Serta tidak ada kemungkinan data rusak atau hilang karena sudah terminimalisir dengan aplikasi ini.

3. Pelanggan sudah tidak kesulitan lagi untuk mengantri dengan pelanggan lain ketika memesan jasa layanan fotografi maupun makeup pada Queen photo studio serta penggunaan waktu menjadi lebih efektif dan efisien, sehingga ke depan pelanggan Queen Fhoto studio semakin banyak dan omsetnya juga semakin meningkat, dan 
Queen juga dapat bersaing dengan perusahan sejenis maupun dengan dengan perusahan yang lain.

Ucapan Terimakasih

Berisi ucapan terima kasih kepada lembaga LPPM STMIK Indonesia Padang dan juga kepada Pimpinan CV. Queen Photo Studio Padang yang telah membantu dalam pelaksanaan penelitian ini.

\section{Daftar Pustaka}

[1] U. Surakarta, "Sistem Informasi Persediaan Keluar Masuk Barang Pada Inside Distro Jakarta Rocky Aji Wibowo Universitas Surakarta," J. Speed - Sentra Penelit. Eng. dan Edukasi - Vol. 1 No 4 - 2009 - ijns.org, vol. 1, no. 4, pp. 19-24, 2009.

[2] D. Metode, S. Studi, P. T. Chingmix, and B. Sejahtera, "Strategi Pengembangan Teknologi E-Commece," J. Telemat. MKOM, Vol.3 No.2, Sept. 2011, vol. 3, no. 2 , 2011.

[3] R. Sri, A. Rejeki, A. P. Utomo, and S. Susanti, "Perancangan dan Pengaplikasian Sistem Penjualan pada 'Distro Smith' Berbasis E - Commerce," J. Teknol. Inf. Din., vol. 16, no. 1, pp. 150-159, 2011.

[4] Sidharta and B. Suzanto, "Pengaruh Kepuasan Transaksi Online Shopping Dan Kepercayaan Konsumen Terhadap Sikap Serta Perilaku Konsumen Pada ECommerce," J. Comput. Bisnis, Vol. 9, No. 1, Juni 2015, 23-36 ISSN 2442-4943, vol. 9, no. 1, pp. 23-36, 2015.

[5] M. Suhartanto, "Pembuatan Website Sekolah Menengah Pertama Negeri 3 Delanggu Dengan Menggunakan Php Dan MySQL Medi Suhartanto," J. Speed - Sentra Penelit. Eng. dan Edukasi, vol. 4, no. 1, pp. 1-8, 2012.

[6] M. Heri Prasetyo and Y. Arliando, "Sistem Informasi Nilai Mahasiswa Berbasis Sms Gateway Pada Fakultas Pertanian Universitas Bengkulu," J. Media Infotama Sist. Inf. Nilai ... ISSN, vol. 11, no. 1, pp. 1858-2680, 2015.

[7] P. Rahma, M. Nasir, and A. Putra, "Implementasi Metode Weighted Product dalam Sistem Pendukung Keputusan Kelayakan Pemberian Tunjangan Profesi Guru Lanjutan pada Dinas Pendidikan Kabupaten Ogan Komering Ilir ( OKI ) Bina Darma Conference on Computer Science 2019," Fak. Ilmu Komput. Univ. Bina Darma, pp. 263-269, 2019.

[8] R. L. M. Agus Umar Hamdani, "Model E-Commerce Dengan Metode Web Enginering Method Untuk Menunjang Pemasaran Produk Pada XYZ Pet Shop," Pros. SENDI_U 2019, pp. 978-979, 2019.

[9] R. V Palit, Y. D. Y. Rindengan, and A. S. M. Lumenta, "Rancangan Sistem Informasi Keuangan Gereja Berbasis Web Di Jemaat GMIM Bukit Moria Malalayang," E-Journal Tek. Elektro dan Komput. vol. 4 no. 7, vol. 4, no. 7, pp. 1-7, 2015.

[10] A. T. Wibowo, "Pembuatan Aplikasi E-Commersce Pusat Oleh-Oleh Khas Pacitan," IJNS - Indones. J. Netw. Secur. - ISSN 2302-5700, vol. 2, pp. 62-67, 2013.

[11] T. Chandrayanti and A. Mulyana, "Model Pengembangan Usaha Kecil Menengah (UKM) Kreatif di Sumatera Barat dengan Pendekatan Terintegrasi Zaman Now," Pros. 4th Semin. Nas. dan Call Pap. 2018 Fak. Ekon. Univ. Muhammadiyah Jember Hal 59-7, pp. 59-70, 2018.

[12] J. Neo-bis and M. Pradana, "Klasifikasi Jenis-Jenis Bisnis -E-Commerce Di Indonesia," J. Nseo-Bi, vol. 9, no. 2, pp. 32-40, 2015.

[13] A. H. Rosdiana , Denny Kurniadi, "Rekayasa Sistem Informasi Promosi Dan Pengolahan Jasa Studio Foto Berbasis Web," VOTEKNIKA J. Vokasional Tek. 
Elektron., vol. 7, no. 2, 2019.

[14] S. Dian and P. Pratiwi, "Sistem Informasi Komunitas Jepret Mentaya Photography Sampit Berbasis Web," J. Penelit. Dosen FIKOM, vol. 7, no. 2, 2017.

[15] G. Jihadi, "Rancang Bangun Sistem Aplikasi Penyewaan Lapangan Futsalis Berbasis Web," Semin. Nas. Teknol. Inf. dan Multimed. 2017 STMIK AMIKOM Yogyakarta, pp. 7-12, 2017.

[16] A. Nugroho, "Perancangan Sistem Informasi Administrasi Jasa Foto," vol. 9, no. ISSN, pp. 196-209.

[17] D. Wira, T. Putra, and R. Andriani, "Unified Modelling Language ( UML ) dalam Perancangan Sistem Informasi Permohonan Pembayaran Restitusi SPPD," $J$. TEKNOIF, vol. 7, no. 1, 2019.

[18] E. S. Erna Kumalasari Nurnawati, "Sosialisasi Manfaat Dan Bahaya Pemakaian Teknologi Informasi di Kalangan Anak-anak," J. Dharma Bakti-LPPM IST AKPRIND Yogyakarta, vol. 1, no. 2, pp. 123-132, 2018.

[19] I. Waspada, "Percepatan adopsi sistem transaksi teknologi informasi untuk meningkatkan aksesibilitas layanan jasa perbankan," J. Keuang. dan Perbankan, Vol.16, No.1 Januari 2012, vol. 16, no. 1, pp. 122-131, 2012.

[20] S. Haryanti and T. Irianto, "Rancang Bangun Sistem Informasi E-Commerce Untuk Usaha Fashion Studi Kasus Omah Mode Kudus," J. Speed - Sentra Penelit. Eng. dan Edukasi, vol. 3, no. 1, pp. 8-14, 2011.

[21] L. Marlinda, A. Hamid, and B. Jamur, "Sistem Informasi Budi Daya Jamur Menggunakan Metode Web Enginering," Semin. Nas. Sains dan Teknol. 2014 Fak. Tek. Univ. Muhammadiyah Jakarta, no. November, pp. 1-4, 2014. 